\title{
Frontalis sling: a modified simple technique
}

\author{
S M BETHARIA \\ From Dr Rajendra Prasad Centre for Ophthalmic Sciences, Ansari Nagar, New Delhi 110029, India
}

SUMmaRY A modified simple technique of brow suspension by using 4-0 Supramid (nonabsorbable thread) suture and only one skin incision is described in 25 eyes of 15 cases of ptosis, including cases of congenital and mechanical ptosis and ptosis with Marcus Gunn phenomenon. This technique avoids the use of any special instruments such as the Reese ptosis knife and Wright needle.

A sling operation is by far the easiest of all ptosis operations to perform. Though it may have important disadvantages, such as the risk of lagophthalmos and lid lag in down gaze, it is the operation of choice for certain cases of gross bilateral ptosis with poor levator function as seen in the blepharophimosis syndrome, cases of mechanical ptosis, and in severe unilateral ptosis covering the pupillary area to prevent amblyopia before a definitive levator operation can be carried out.

Various kinds of material have been used for sling surgery, including skin muscle flaps, non-absorbable sutures, preserved sclera, reconstituted collagen, Silastic bands, and fascia lata. Bodian' used strips of human sclera successfully, whereas Iliff ${ }^{2}$ advocated the use of reconstituted collagen. Helveston and Wilson ${ }^{3}$ used strips of sclera woven with 4-0 Supramid for passing the sling. Tillet and Tillet ${ }^{4}$ used a silicone sling, and Callahan ${ }^{5}$ used a Silastic band for frontalis suspension. Crawford ${ }^{6}$ and Fox ${ }^{7}$ advocated the use of fascia lata.

Methods of passing the sling have been described. ${ }^{6-8}$ The slings were rhomboidal or pentagonal in shape, and multiple incisions were made during the operation. Most of these methods are tedious and require special instruments such as a fascia lata stripper, a Wright needle, and a Reese ptosis knife for the operation, and they leave ugly scars.

\section{Materials and methods}

A modified simple technique of brow suspension is described below which has been carried out successfully on 25 eyes in 15 cases of blepharophimosis with gross ptosis, mechanical ptosis, and ptosis associated

Correspondence to Dr S M Betharia, Dr Rajendra Prasad Centre for Ophthalmic Sciences, New Delhi 110029, India. with the Marcus Gunn phenomenon after disinsertion of levator muscle from the tarsal plate (Table 1).

\section{SURGICAL PROCEDURE}

The operation is carried out under general anaesthesia. The first step is to lift the lid with the help of the index finger just medial to the centre of the upper lid and observe the contour of the lid margin in relation to the limbus. This gives an approximate idea of the place from which the needle has to be passed. A $5 \mathrm{~mm}$ wide bite is taken about $4 \mathrm{~mm}$ away from the lid margin by using a $15 \mathrm{~mm}$ curved cutting needle carrying 4-0 Supramid suture. This bite is taken through the orbicularis and the pretarsal tissue (Fig. 1). The needle is taken out and re-entered through the same point from which it has emerged and carried upwards through the plane between the orbicularis and the levator and through the single incision made above the brow (Figs. 2,3). The other arm of the suture is similarly carried through by using a similar needle which enters through the initial opening made by the needle and is then brought out through the incision above the brow (Figs. 4, 5). A single knot is first tied, the lid is lifted, and the contour of the lid margin in relation to the limbus is observed. The tension on the two arms of the

Table 1 Distribution of cases

\begin{tabular}{|c|c|c|}
\hline Diagnosis & $\begin{array}{l}\text { No. of } \\
\text { cases }\end{array}$ & Operation done \\
\hline Blepharophimosis syndrome & 10 & Bilateral sling \\
\hline $\begin{array}{l}\text { Congenital ptosis with Marcus } \\
\text { Gunn phenomenon }\end{array}$ & 2 & $\begin{array}{l}\text { Unilateral sling after } \\
\text { disinsertion of the } \\
\text { laevator }\end{array}$ \\
\hline $\begin{array}{l}\text { Mechanical ptosis (haemangioma } \\
\text { and neurofibroma) }\end{array}$ & 3 & Unilateral sling \\
\hline
\end{tabular}




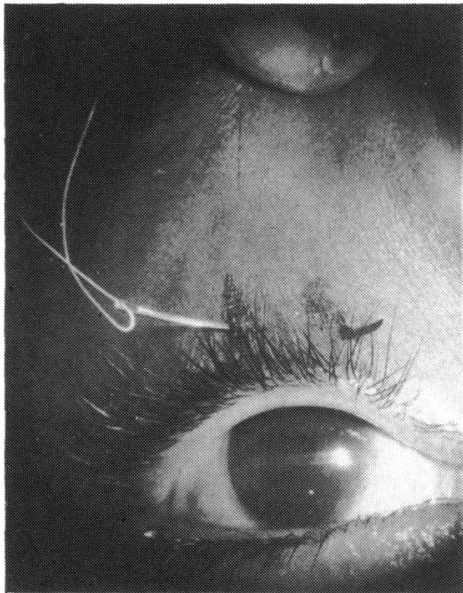

Fig. 1

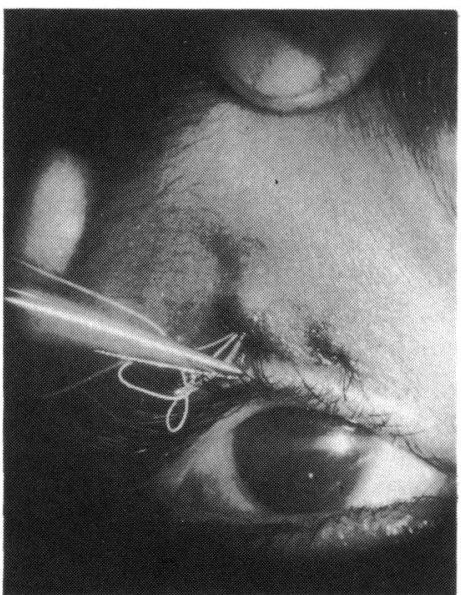

Fig. 4

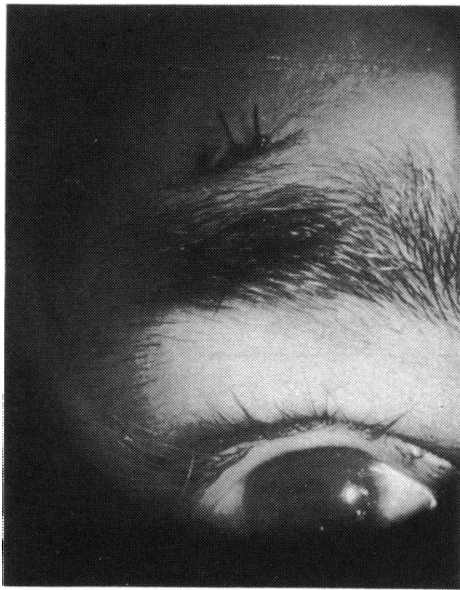

Fig. 7

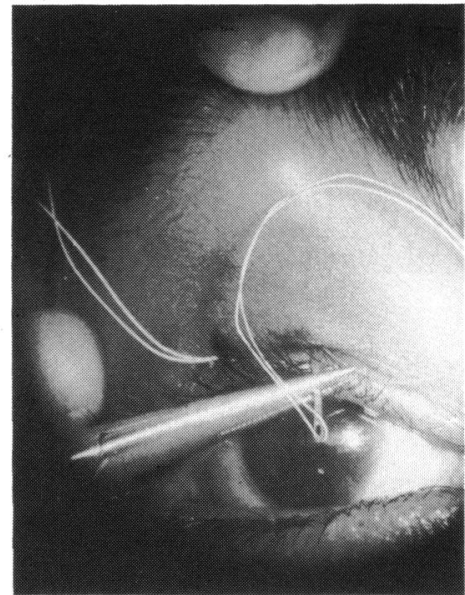

Fig. 2

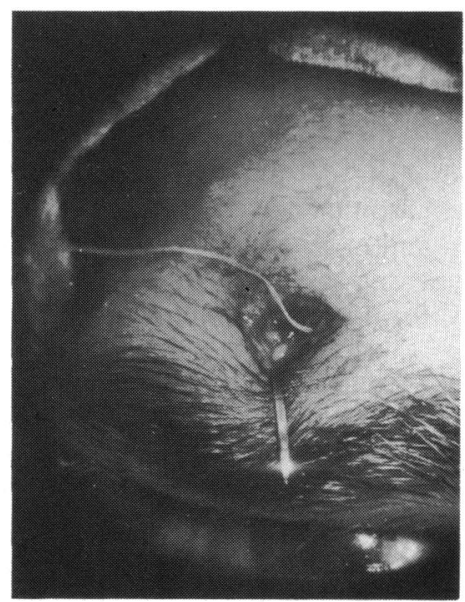

Fig. 5

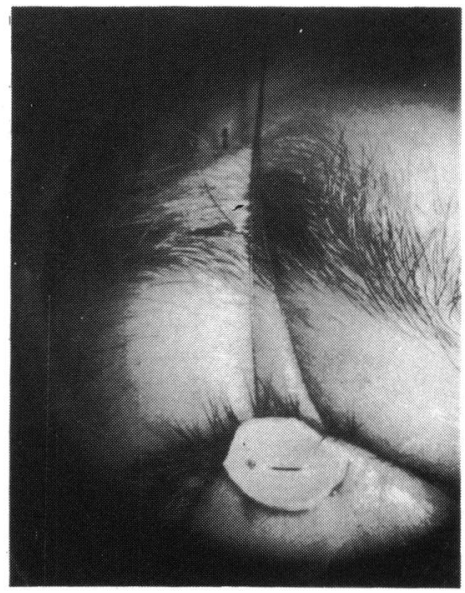

Fig. 8

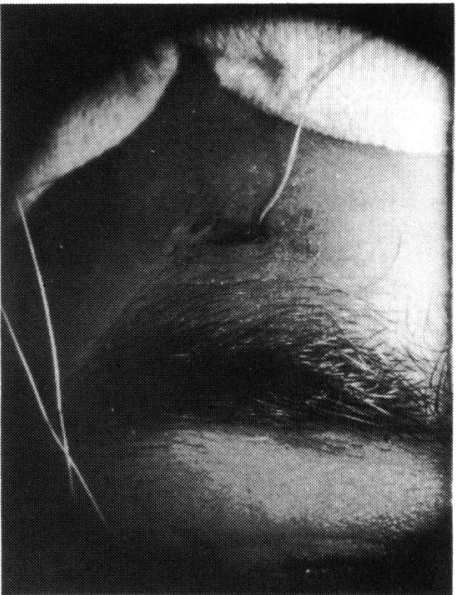

Fig. 3

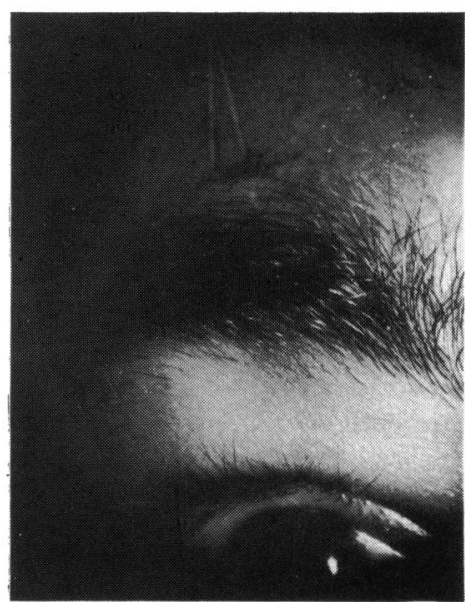

Fig. 6

Figs. 1 to 8 Steps of the modified frontalis sling operation. 


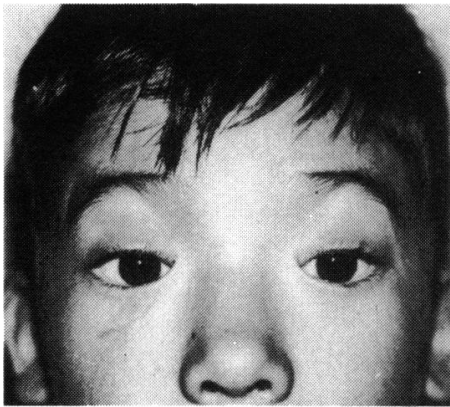

Fig. 9 Preoperative photograph of a case of blepharophimosis syndrome. Note the arching of brows and wrinkles on the forehead suggesting frontalis overaction.

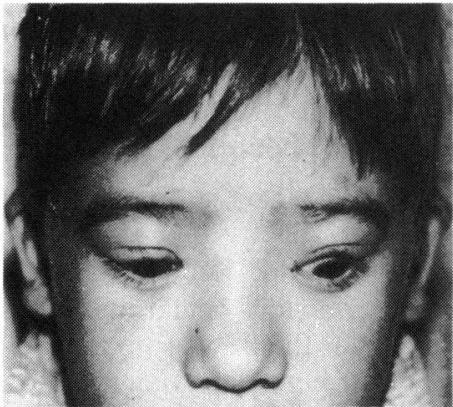

Fig. 12 Showing reduction in the lid lag after three months.

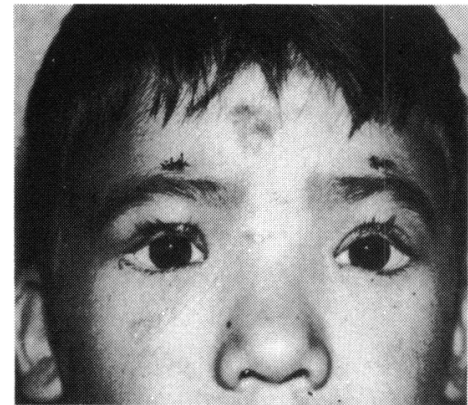

Fig. 10 Early postoperative photograph showing a good symmetrical correction with good lid fold.

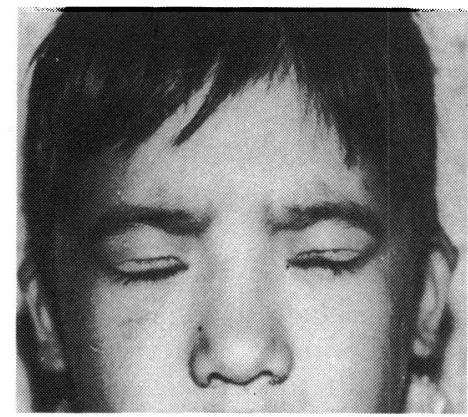

Fig. 13 Showing very minimal lagophthalmos after the modified sling operation.

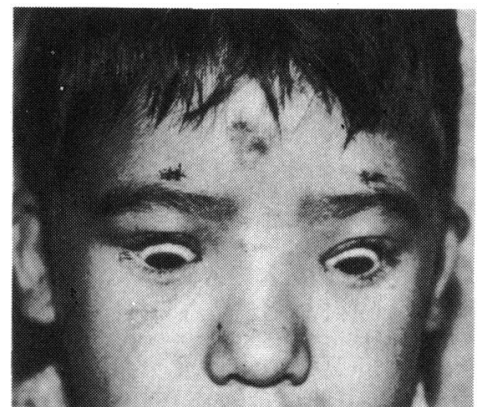

Fig. 11 Showing marked lid lag in early postoperative period.

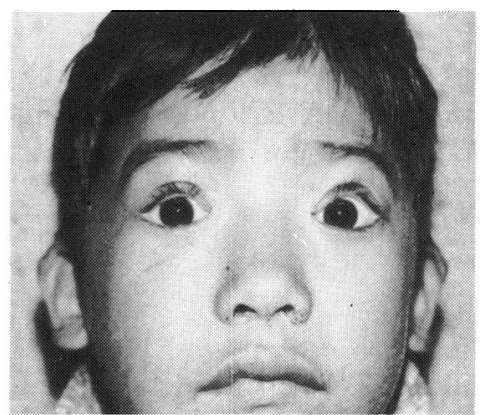

Fig. 14 Postoperative photograph after three months showing good correction in primary gaze. suture is so adjusted that there is no central notching or ectropion (Fig. 6). Three square knots are tied, and the skin incision is closed with 5-0 black silk (Fig. 7). A modified Frost suture is finally made (Fig. 8).

\section{Results and discussion}

Of 15 cases operated upon so far by this technique only one had suture granuloma and infection. The lid lag, which was quite marked at the beginning, was much reduced after three months. The lagophthalmos was minimal. A good symmetrical lift with a good lid fold was obtained (Figs. 9 to 14). All the cases were followed up postoperatively for three to nine months, average six months.

This method employs only one skin incision as against six in Crawford's technique ${ }^{6}$ of double rhomboids and five in Fox's method,' thereby reducing the possibility of scar marks. The central $5 \mathrm{~mm}$ bite through the orbicularis and pretarsal tissue eliminates the central notching, while the peripheral parts of the lid on the medial and lateral sides are lifted properly, and the contour of the lid can be correctly adjusted by pulling on the two arms of the suture. A good lid fold and symmetry were achieved by this technique. The lid lag, which was marked in the initial postoperative period, was reduced to a minimum, and there was minimal lagophthalmos. This method is extremely simple and required no special instruments.

\section{References}

1 Bodian M. Repair of ptosis using human sclera. Am J Ophthalmol $1968 ; 65: 352-8$.

2 Iliff CE. Surgical management of ptosis. Somerville, NJ: Ethicon, 1963: 9-12.

3 Helveston EM, Wilson DL. A suture reinforced scleral sling. Arch Ophthalmol 1975; 93: 643-5.

4 Tillet CW, Tillet GM. Silicone sling in correction of ptosis. Am J Ophthalmol 1963; 62: 521-3.

5 Callahan A. Correction of unilateral blepharoptosis with bilateral eyelid suspension. Am J. Ophthalmol 1972; 74: 321-6.

6 Crawford JS. Repair of ptosis using frontalis muscle and fascia lata. Trans Am Acad Ophthalmol Otolaryngol 1956; 60: 672-8.

7 Fox SA. Complications of frontalis sling surgery. Am J Ophthalmol 1967; 63: 758-62.

8 Friedenwald JS, Guyton JS. A simple ptosis operation: utilization of the frontalis by means of a simple rhomboid shaped suture. Am J Ophthalmol 1948; 31: 411-4. 